\title{
Distributed generation and the regulation of distribution networks ${ }^{1}$
}

\author{
Jeroen de Joode ${ }^{1,2}$, Adriaan van der Welle ${ }^{1}$ and Jaap Jansen ${ }^{1}$ \\ ${ }^{1}$ Energy research Centre of the Netherlands (ECN) \\ Petten \\ ${ }^{2}$ Faculty of Technology, Policy and Management, Delft University of Technology \\ Delft \\ The Netherlands
}

\section{Introduction}

Electricity systems around the world are experiencing an increase in the amount of distributed electricity generation for a variety of reasons. In general the two main driving forces for a further penetration of distributed electricity generation in energy systems are market liberalisation and environmental concerns (Pepermans et al., 2005; Peças Lopes et al., 2007). Distributed electricity generation allows electricity system actors more flexibility in dealing with changing market conditions and can have favourable environmental characteristics due to its renewable character (e.g. small-scale wind turbines and photovoltaics) or the efficient combination of electricity and heat production (e.g. small-scale combined heat and power (CHP) units). With an increasing attention for renewable electricity generation and energy efficiency improvements in energy policy the future will continue to see an increase in the share of distributed electricity generation in electricity systems.

In projections on future electricity system developments the amount of distributed electricity generation is generally not explicitly presented. As an approximation we can use projections on the amount of specific generation technologies of which at least part is integrated in the electricity system at the distributed level. Figure 1 shows projections for generation capacity based on renewable electricity technologies, as well as CHP, for the European Union (EU) (EC, 2008). Although the actual amount of distributed generation in

\footnotetext{
1 Parts of this contribution are based on De Joode et al. (2009). We thank Martin Scheepers for cooperation in the research that led to this contribution. Furthermore we acknowledge the support of the IEE programme of the European Commission (contract no. EIE/04/015/S07.38553) and the Next Generation Infrastructures Foundation (www.nginfra.nl). The sole responsibility for the content of this contribution lies with the authors. It does not represent the opinion of the Community. The European Commission is not responsible for any use that may be made of the information contained therein.
} 
the EU in the period until 2030 is uncertain, it is highly likely that the increase in renewablebased and CHP-based electricity generation will also be reflected in the developments on the distributed level.

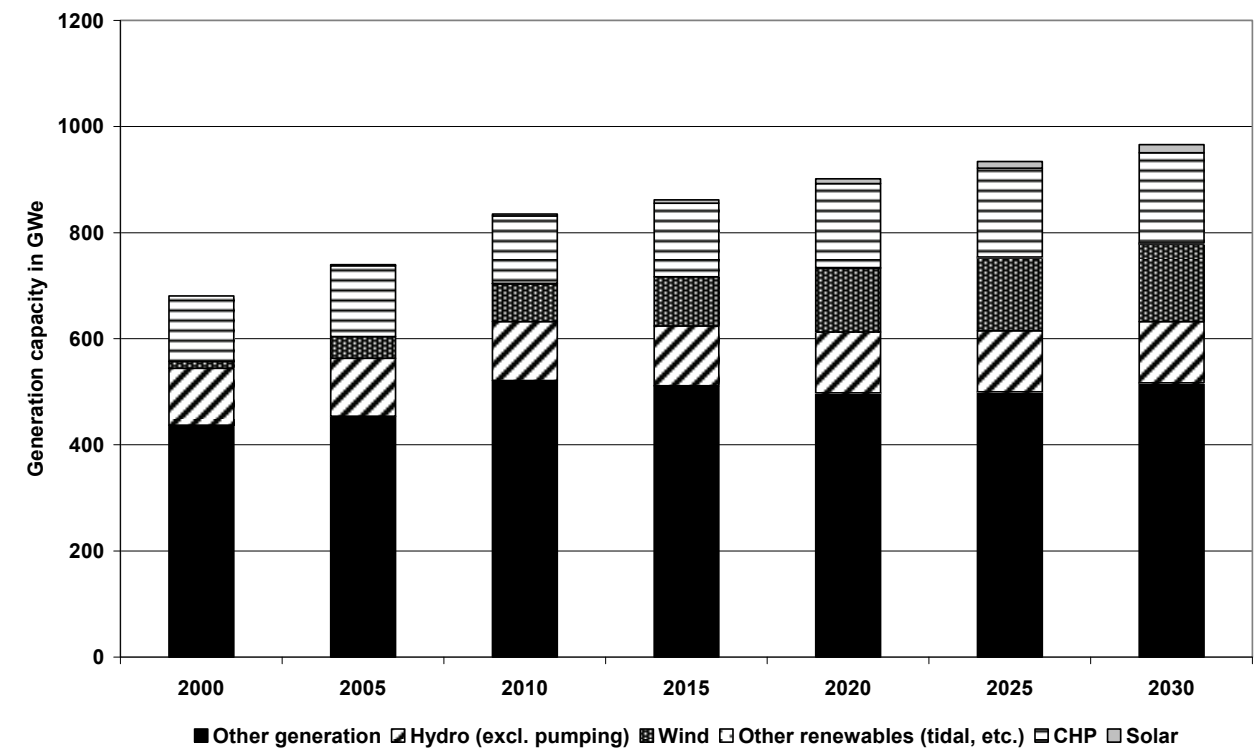

Fig. 1. Projections for future electricity generation capacity in the EU-27 (EC, 2008)

The trend towards a larger share of distributed electricity generation in electricity systems creates both opportunities and challenges (Peças Lopes et al., 2007) and impacts different electricity system actors (e.g. consumers, producers, network operators) in different ways. ${ }^{2}$ A successful transformation of the current electricity system designed around large-scale centralised electricity generation towards a future electricity system with a large role of small-scale distributed electricity generation requires a efficient integration of distributed generation from two perspectives: market integration and network integration. Market integration issues surrounding distributed generation relate to the access of producers of distributed electricity generation to electricity markets and institutional and contractual arrangements of the producers with other electricity market actors. Network integration of distributed generation is about operating the electricity system, including network flows from the connection of new distributed generation units, in an efficient manner.

Challenges in successfully integrating distributed generation in electricity systems are technical, commercial or regulatory in nature (Peças Lopes et al., 2007; Strbac, 2002). In this contribution we focus on the regulatory challenges. Most electricity systems throughout the world have been liberalised. European electricity markets have been in a process of liberalisation since 1998. However, due to natural monopoly characteristics the network

2 Barth et al. (2008) discuss the allocation of costs due to the integration of an increasing amount of renewable electricity generation over electricity market actors. 
related part of the system has remained regulated (Joskow, 2005). This includes the lower voltage distribution networks where distributed generation is connected. We explain the concept of natural monopolies in more detail in Section 2.4. The Distribution System Operator (DSO) has the task to facilitate both the connection of distributed generation to the network, and the feed-in of electricity from distributed generation in the network. More in general the DSO bears responsibility for planning, operating and maintaining the distribution network. The DSO is not responsibly for the supply of electricity to endconsumers. This task rests with the electricity retail companies. A large(r) cost burden for the DSO could very well act as a barrier in the continuing integration of distributed generation in electricity systems if distributed generation is not explicitly included in the design and application of network regulation (Woodman and Baker, 2008). It is therefore important to have a good understanding of how distribution network regulation affects the further integration of distributed generation. Just as the electricity system itself, distribution network regulation was designed in an era where large-scale centralised electricity generation was the standard and distribution networks were primarily used for the distribution of electricity flows from higher voltage networks to end-consumers.

An important aspect of analysing the regulatory challenge in integrating more and more distributed generation is the way in which distribution networks are managed. There is a distinction between passive network management and active network management. The current network management approach is based on an equal treatment of both consumers and distributed generators that want to be connected to the distribution network. New distributed generation connections influence electricity flows in the distribution network. The network needs to be dimensioned on peak generating capacity of the distributed generation unit resulting, in some cases, in incremental reinforcement in the network by the DSO. This is also called the passive network management approach, or 'fit and forget' approach: when distributed generation enters the distribution network, upgrade investments based on peak distributed generation output are undertaken and for the remainder any electricity production from the unit is taken as given. An alternative approach is provided with an active network management philosophy (McDonald, 2008). This approach is based on the concept of intelligent networks where technological innovations on power equipment and ICT are combined to allow for a more efficient use of distribution network capacity, for instance by network reconfiguration. In addition, it is characterised by active involvement of both consumers and distributed generators: load and generation characteristics are taken into account in network operation and planning. When confronted with new connections the active DSO explicitly recognizes the network contribution of electricity consuming and producing entities in its network planning and includes this in investment decision-making. The hypothesis is that integrating distributed generation in distribution networks can be done more cost effective in networks operating under active network management compared to networks operating under passive network management. Therefore, adapting distribution network regulation to efficiently accommodate more and more distributed generation might include the facilitation of a transformation in network management approach as well as a potential compensation for financial impacts. 
The main hypothesis in this contribution is that current regulation of distribution networks needs to be revised in order for a continuing integration of distributed generation in electricity systems in an efficient manner. We support this hypothesis by providing a systematic overview of the financial impact of distributed generation on the DSO using available literature and by providing a model-based analysis.

In the remainder we proceed as follows. Section 2 presents definitions. Section 3 discusses the impact of an increasing amount of distributed generation in the distribution network on the financial position of the DSO. In Section 4 we deal with methodological issues. We more precisely define the object of study and scope of this contribution and present the methodology applied. Section 5 presents the results of our research on the economic impact of distributed generation on the owner and operator of the distribution network and the impact of changes in distribution network regulation on this economic impact. Section 6 discusses the results and Section 7 provides some recommendations for both policy and regulation and future research.

\section{Definitions}

Our focus in this contribution is on the relationship between the integration of distributed generation and distribution network regulation. We first of all need to provide a more precise definition of distributed generation, distribution networks, regulation, and passive and active network management.

\subsection{Distributed generation}

Note that distributed generation may also be referred to as 'dispersed generation', 'embedded generation', or 'decentralised generation'. In combination with demand response and energy storage it is sometimes referred to as 'distributed energy resources'.

\begin{tabular}{lll}
\hline & Combined Heat and Power (CHP) & Renewable Energy Sources (RES) \\
\hline Large scale & - Large district heating & - Large hydro \\
generation & - Large industrial CHP a & - Offshore wind \\
& & - Onshore wind (partly) \\
& & - Co-firing biomass in coal power \\
& & - plants \\
& & - Geothermal energy \\
Distributed & - Medium district heating & - Medium and small hydro \\
Generation & - Medium industrial CHP & - On-shore wind (partly) \\
(DG) & - Commercial CHP & - Tidal energy \\
& - Micro CHP & - Biomass and waste \\
& & incineration/gasification \\
& & - Solar energy (PV)
\end{tabular}

Table 1. Characterisation of electricity generation units (Scheepers, 2004)

a typically $>50 \mathrm{MW}_{\mathrm{e}}$

b typically $>10 \mathrm{MW}_{\mathrm{e}}$

We follow Ackermann et al. (2001) in defining distributed generation as: "Distributed generation is an electric power source connected directly to the distribution network or on the customer site of the meter". It is difficult to provide a universal definition in a 
quantitative sense because this is country specific and relates to characteristics of the centralised electricity system. Co-generation (or CHP) and electricity generated from renewable energy sources (RES) are often considered as distributed generation. However, as is shown in Table 1, only a part of CHP and RES can be considered as distributed generation.

\subsection{Distribution networks}

Ackermann et al. (2001) discuss the concept of distribution networks. They note that distribution networks have been designed with a different purpose than transmission networks: they were generally not designed to connect power generation devices. Another general characteristic of distribution networks as in contrast to transmission networks is the often radial or loop design. Transmission networks generally have a meshed design. What constitutes a distribution network from an institutional / regulatory perspective is less clear: the term distribution network is not fixed to specific voltage levels. A specific voltage level network that is considered to be part of the distribution network in the one jurisdiction can be considered to be part of the transmission network in another.

\subsection{Distribution network regulation}

The distribution of electricity is considered to be a natural monopoly due to economic characteristics. The distribution of electricity is highly asset-specific involving a large share of capital expenditures relative to operational expenditures, and concerns long lifetime of investment. In other words: general textbook economics does not apply here (Joskow, 2005). Prevailing distribution network regulation regimes across EU countries prevent DSOs from acting as a monopolist. Among others, tariff conditions for distribution network services are under regulatory scrutiny via revenue of price cap regulation. For a discussion on the types of network regulation in electricity distribution we refer to Joskow (2006) and Rudnick and Donoso (2000). When talking about regulation in the context of electricity distribution networks we distinguish two basic elements: the regulation of access conditions and the regulation of distribution network connection conditions. Both types of conditions relate to the distribution network service provision to both consumers and producers.

Firstly, access conditions in general encompass third party access to distribution networks. E.g. all parties wishing to contract distribution network services should be allowed to do so on a non-discriminatory basis. Basically, it is the regulatory authority that approves the level of charges. Charges for the use of the distribution network are generally referred to use of system (UoS) charges. An important aspect of distribution network regulation is the differential allocation of overall system costs to producers and consumers. For example, in some jurisdictions electricity producers are not charged use of system charge. In fact, in about half of the EU countries distributed generation does not pay UoS charges (Cossent et al, 2009). Furthermore there are differences in the design of UoS charges across electricity systems, for example in the degree in which system costs are covered by fixed UoS charges (e.g. capacity dependent charge) or variable UoS charges (e.g. charges dependent on feed-in or consumption). 
Secondly, there are different approaches with respect to connection conditions. In principle, a DSO is always obliged to connect consumers or producers to its distribution network, but different approaches exist in the allocation of costs incurred by the new connection. Three different approaches exist: shallow connection charging, shallowish connection charging, and deep connection charging. Under a regime of shallow connection charging the consumer or producer connected to the network is only charged a limited part the costs related to connection, for example only the on-site costs of connection. Under a deep connection regime the consumer or producer is charged not only the full cost of connecting to the existing distribution network, but if applicable also the costs of network upgrades elsewhere in the distribution network that are required to accommodate the future electricity flow resulting from the new connection. A shallowish connection regime is somewhere in-between the former two categories: the consumer or producer is charged only part of the deep network cost. Connection costs that are not covered by charges to the consumer or producer are socialised, meaning that costs are recovered via general UoS charges. Regulation may differentiate in the connection charging regime to be applied to particular consumers or producers, for example based on yearly off take or the electrical capacity of the connection. In our model-based analysis in Section 4 we assume a regulatory regime based on shallow connection charging since the majority of EU member states apply shallow or 'shallowish' connection charging on the distribution network level (Cossent et al, 2009).

\section{Background}

The increasing penetration of distributed generation impacts the financial position of the DSO in a number of ways. Figure 2 provides an overview of the economic position of the DSO by listing its revenues and expenditure items.

Revenues for the DSO are generally regulated via either revenue or price cap regimes and consist of revenues from connection charges and revenues from UoS charges. The expenditures of the DSO are divided into two categories: (a) capital expenditures, and (b) operational expenditures. Capital expenditures include investments in distribution network assets such as transformers, switchboards, and cables, and the consequential depreciation costs and remuneration of debt. Operational expenditures encompass costs due to use of the transmission network, distribution losses, costs of ancillary services, and operational and maintenance costs of assets.

Connecting distributed generation units to the existing distribution network implies an increase in the direct (investment) costs of connecting. Under a shallow connection charge regime this can imply an increase in capital expenditures of the DSO. Under a deep or shallowish connection charging regime there is no impact on the DSO because costs are passed-through to the owner of the distributed generation unit. The increased number of distributed generation units in the distribution network can also give rise to additional network investment elsewhere in the network, especially in a situation where the DSO is operating under a passive network management approach where the network is designed based on deterministic rules for minimum and maximum generation and consumption. When an active network management approach is adopted the investment cost impact of 
distributed generation on distribution networks might change compared to the passive network management approach. When distributed generation is located near final consumers, the net electricity demand to be accommodated via the transmission and distribution networks decreases. This implies a reduced need for existing network capacity. In this respect we refer to the 'deferred investment value' of distributed generation. It can be defined as the value of postponing the need to reinforce the system in case of load growth or reducing the investment required in case of equipment replacement (Cao et al., 2006; Méndez et al., 2006a; Jil \& Goos, 2006). In short, the impact of distributed generation on DSO investment expenditures may be positive or negative dependent on network characteristics, type of network management operation and dynamics in the distribution network (e.g. electricity demand growth and need for asset replacement).

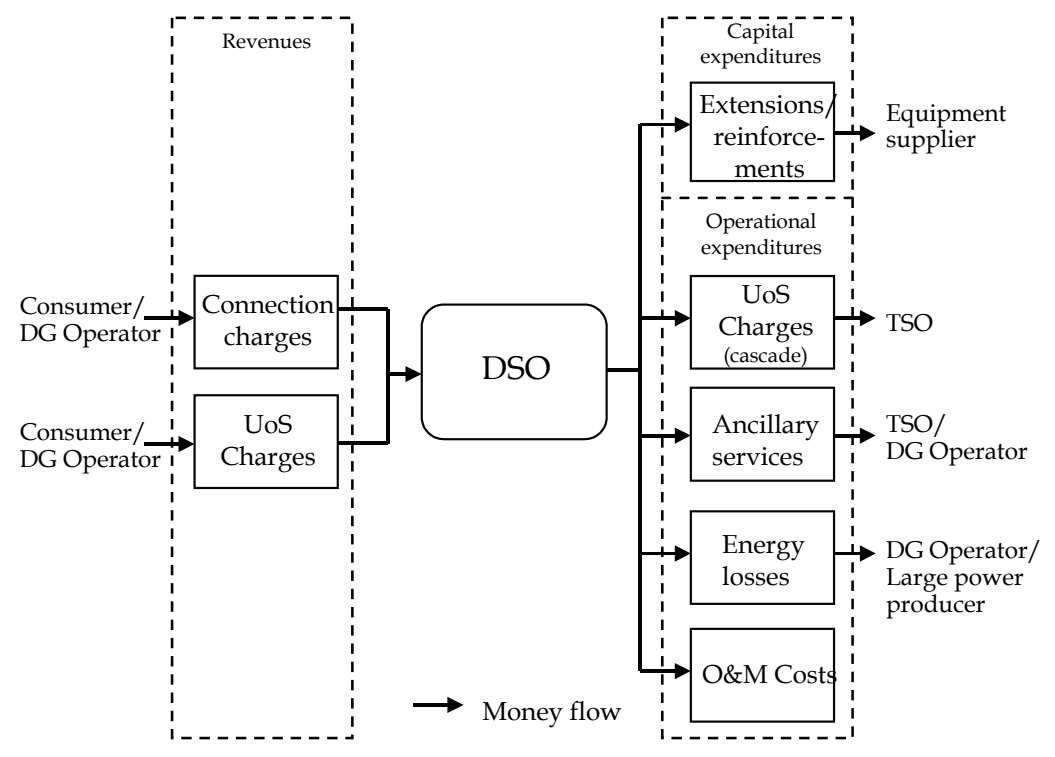

Fig. 2. Overview of DSO revenues and expenditures

The DSO expenditures on UoS charges for the transmission system are a matter of accounting. Final electricity consumers and in some countries also (distributed) generators connected to the distribution network pay for the use of the electricity transmission system to the DSO. The DSO passes-through these revenues to the transmission system operator. An increase in the amount of distributed generation may indirectly affect the level of the charge of the use of the transmission system but will not give rise to an improved or worsened financial position of the DSO.

For the procurement of ancillary services the DSO pays charges to the Transmission System Operator (TSO). Procured ancillary services can include the provision of frequency response, reactive power and regulating and standing reserve (Peças Lopes et al., 2007). Increasing penetration of distributed generation in distribution networks can negatively 
impact the power quality within the network and thus create a larger need for particular ancillary services.

Dependent on the total amount of distributed generation, the size of distributed generation units and the dispersion of the units within a distribution network an increase in distributed generation can either decrease or increase the level of distribution losses. Méndez et al. (2006b) find that in general distributed generation decreases distribution losses when the overall level of distributed generation is low and when distribution networks are characterised by large distances between connections, as is for example the case for distribution networks in rural areas. For higher levels of distributed generation the impact on distribution losses can actually turn negative. The same tends to hold for distribution networks where the distances between connections are shorter, as is for example the case for distribution networks in urban areas.

The level of maintenance costs can be related to the amount of distribution network assets of the DSO. Analogue to the impact of distributed generation on the need for additional distribution network investment the level of maintenance costs may de- or increase with the amount of distributed generation in the distribution network. It is more difficult to assess the impact of an increasing penetration of distributed generation on operational cost. Furthermore, the impact can differ between networks operated under passive and active network management. In a more actively managed distribution network where there is a larger role for intelligent metering and ICT assets the operational costs might increase.

\section{Methodology}

In order to evaluate the impact of an increasing penetration of distributed electricity generators on the DSO we deploy a combination of two different models; a load flow-based generic distribution network model and a financial model representing the financial position of the DSO. Figure 3 shows the basic input-output relation between the generic distribution network model and the DSO financial model. 


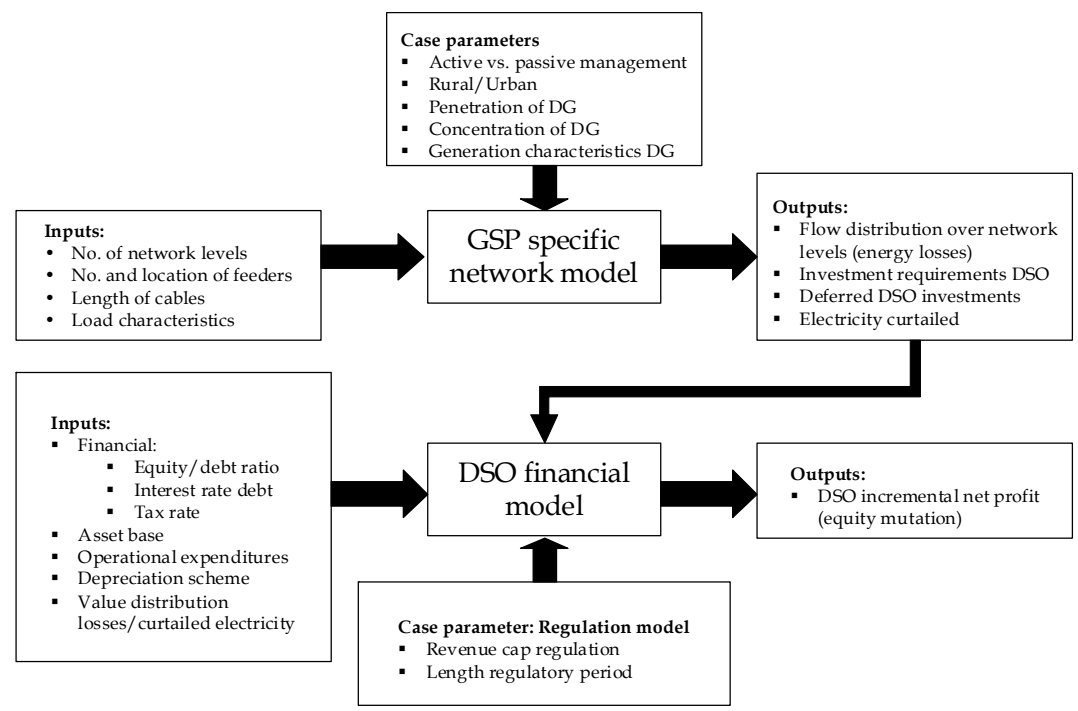

Fig. 3. Schematic overview of the linkages between the generic network model and the DSO financial model

\subsection{Distribution network model (GSP)}

The generic distribution network model is based on the topology and design of an 'average' UK distribution network that is connected to a 'grid supply point' (GSP). The distribution network consists of various cascading low voltage level networks with substations and transformers between each of these networks. The voltage networks are modelled as radial networks from the GSP to the end-users. A graphical representation of a generic distribution network, with various loads and distributed generators connected, is shown in Figure 4. In our analysis, the distribution network is dimensioned at a total load of 1155 GWh per year (being equal to the load of one grid supply point). Here we do not discuss the model further in depth. For an extensive model and data input description we refer to Pudjianto et al. (2006).

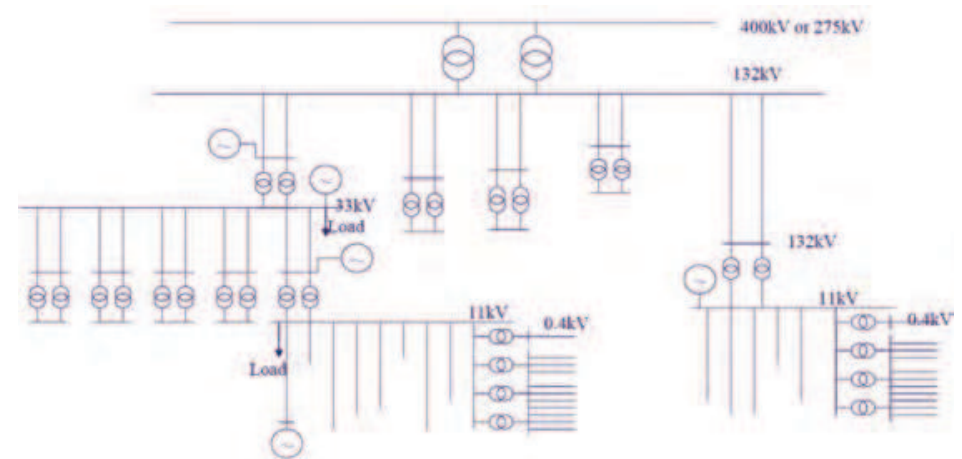

Fig. 4. Representation of the module-based distribution network design in the generic distribution network model (Pudjianto et al., 2006) 


\subsection{DSO financial model}

The DSO revenue and expenditure model contains the revenue and expenditure items of the DSO and calculates net profit over a longer period of time. The model has the following basic characteristics. First, the model is incremental in the sense that it does not explicate the costs and revenues related to 'business as usual' but only the incremental costs and revenues caused by the increase of distributed generation in the distribution network. This enables a strict assessment of the impact of DG on the DSO. Second, the model is dynamic: it captures a number of regulatory periods with each covering a number of years. This approach is in line with current practice where the DSO, being a regulated actor, is confronted with a network performance assessment by the regulatory authority once per regulatory period. Third, the specific regime of distribution network regulation assumed to apply for the studied DSO is based on incentive based regulation and more in particular, based on a revenue-cap system. Our choice for this specific regime can be justified by an EU wide observed tendency to move from traditional cost-plus regimes to incentive based regimes (Skytte and Ropenus, 2007). Below we go into more detail on this type of distribution network regulation since this is vital for the remainder of this contribution.

Incentive based regulation trough a revenue cap basically implies the following: the DSO is only allowed to receive a maximum total allowed revenue (TAR) in return for the provision of distribution network services in a year, with the TAR in one year being equal to the TAR in the previous period corrected for (i) a requirement on improved efficiency performance, (ii) change in overall price level (inflation), and (iii) optional compensation schemes for adverse developments in demand. Since the DSO model uses and presents real prices the revenue cap scheme included in the DSO model does not contain a correction for inflation. The foregoing results in the following formula:

$$
T A R_{t}=T A R_{t-1}(1-X) \pm A F
$$

where:

$T A R_{t}=$ Total allowed revenue in year $t$

$X \quad=$ Required yearly improvement in efficiency performance

$A F=$ Adjustment factor

The total allowed revenue in the starting year is dependent on the capital expenditures consisting of the total regulated asset base (RAB) and the weighted average cost of capital (WACC), as well as the operational expenditures. The RAB represents the value of the DSOs asset base.

$$
T A R_{0}=f(R A B, W A C C, O P E X)
$$

In traditional incentive-based regulation DSOs are remunerated according to their outputs (the services they deliver). These outputs are usually compared to each other with benchmarking. Often these benchmarking exercises do not take into account the structural differences between regions with respect to distributed generation penetration, 
concentration and the distance between distributed generation and demand. In other countries not all new investments are fully included in the regulatory asset based: i.e. no automatic pass-through of investment costs to end-consumers is allowed for. The only exception is the UK, which disposes of a special rule regarding the remuneration of distributed generation related investment. Consequently, in the remaining analysis we assume that DSOs do not fully recover the costs of distributed generation related incremental network reinforcement costs.

\subsection{Case parameters}

In order to explore the impact of the increasing penetration of distributed generation on the financial position of the DSO we identify different case parameters that simulate different conditions under which DSOs are facing increasing penetration of distributed generation. We use the following case parameters: different levels of distributed generation in the network, different concentration levels for distributed generation units, different levels of less controllable type of distribution generation, different network topologies and different types of network management. Below, we briefly comment on each case parameter.

Firstly, the amount of distributed generation in the network indicates the amount of peak distributed generation capacity in the network. This amount ranges from 50 to 100 to 200 MW. Given the total level of demand of 1155 GWh in the distribution network, and assumed load factors for intermittent (30\%) and non-intermittent $(60 \%)$ distributed electricity generation, this results in a penetration rate in the range of 10 to $90 \%$ of total load. Secondly, the concentration of distributed generation capacity indicates whether the spatial concentration of distributed generation within the distribution network is either high or low, where concentration refers to the physical location of the distributed generation unit. Thirdly, the share of intermittent generation in total distributed generation capacity is considered an important case parameter. Distributed electricity producing units vary in electricity generation profile; whereas some distributed generation units can produce at relatively constant rate, others are volatile in electricity generation. The former category of units is referred to as non-intermittent distributed generation; the latter is referred to as intermittent distributed generation. A related distinction is between controllable and noncontrollable distributed generation units in the sense that distributed generation units producing electricity intermittently can in principle be controllable. For example, small-scale $\mathrm{CHP}$ units at industrial sites are in principal controllable (and hence can respond to changes in electricity prices) but since their electricity production follows industrial heat demand, the resulting electricity production profile is referred to as being intermittent. Within the generic distribution network model, all distributed generation connected to the distribution network is either fully non-intermittent or fully intermittent and there is no distinction between controllable and non-controllable, which is a simplification of reality where an indefinite portfolio of distributed generation units with different electricity generating profiles exist. Hence, in our analysis we explore the two extremes of $0 \%$ intermittency of total distributed generation capacity and $100 \%$ intermittency of total distributed generation capacity. Fourthly, we consider the type of network to be of influence when assessing the impact of distributed generation penetration on the distribution network. A rural network typically consists of longer lines and less concentrated loads than urban networks. Jenkins et al. (2000) mention two different technical barriers for increasing levels of distributed 
generation. In rural areas voltage management and thermal rating issues can hinder further deployment of distributed generation, whether urban areas experience system fault level issues. This implies different requirements for DSO investments in both networks. Fifthly and lastly the type of network management approach, passive or active bears impact on the way in which distributed generation is integrated in the distribution system. Passive network management can be described as a 'fit and forget' network management approach where network requirements caused by new distributed generation connections are met before distributed generation installation by 'simple' capacity expansion. Active network management on the other hand uses 'intelligence' in the network to cope with the operation of new distributed generation in real-time.

We have analyzed the impact of distributed generation penetration on the financial position of the DSO for a limited number of cases. Table 2 gives an overview of the studied cases and the taken values for the earlier described case parameters. The different cases can be interpreted as different type of distribution networks / distribution system operators.

\begin{tabular}{lll}
\hline Case parameter & Values & Unit \\
\hline 1. Level of distributed generation & {$[50,100,200]$} & {$[\mathrm{MW}]$} \\
2. Concentration of distributed generation & {$[\mathrm{low}$, high] } & [discrete] \\
3. Share of intermittent generation & {$[0,100]$} & {$[\%]$} \\
4. Type of network & [rural, urban] & [discrete] \\
5. Type of network management & [passive, active] & [discrete] \\
\hline
\end{tabular}

Table 2. Overview of analysed cases and their parameter values

\section{Analysis and results}

\subsection{Impact of distributed generation on the DSO}

The impact of increasing the amount of distributed generation in a distribution network on the (regulated) financial position of the DSO is indicated as a percentage change in the financial position (net profit) of the DSO as compared to a situation where no distributed generation enters the distribution network. Table 3 presents the results of our analysis.

Recall that costs and revenues resulting from 'normal' business, i.e. a distribution network where no distributed generation is present in the network, are not analyzed: the financial model is incremental in nature. For example, for the first case we find that an integration of $100 \mathrm{MW}$ of concentrated and intermittent distributed generation capacity in a rural distribution network operated under a passive network management philosophy, results in a $7.8 \%$ increase in net profit for the DSO compared to the no distributed generation penetration case. ${ }^{3}$ The table reports two results: one including and one excluding the potential replacement value of integrated distributed generation. The replacement value is created when distributed generation penetration at one point in time, prevents or defers the (replacement) investment in network capacity upgrades at a later point in time. For example, continuous load growth due to increasing electricity demand would in due time

3 We do not necessarily need to have full knowledge of all costs and revenues in the reference case as long as we do include all relevant cost and revenue items (i.e. items that change as a result of the increasing penetration of distributed generation). 
require new investments in the substation that connects the distribution with the transmission network, unless increasing distributed generation levels within the network could cover the additional load growth. Hence, due to the uncertain development of load growth in the distribution network and the technical state of electrical equipment we choose to present a result including $0 \%$ and $100 \%$ of the potential replacement value. In reality, the actual value will be somewhere in-between.

Results show that, if the potential value of deferred investments is not taken into account, DSOs operating under a passive network management regime generally do not profit from the presence of distributed generation in their distribution network. Although low distributed generation penetration levels do benefit the DSO somewhat, higher penetration levels result in a negative overall impact. The concentration of distributed generation within the network is a particular influential factor: the more concentrated the presence of distributed generation in the distribution network, the more negative the impact. The driver for the generally positive results for low penetration levels and the generally negative results for high penetration levels are distribution losses.

DSOs operating under an active network management philosophy are generally confronted with comparable results as the passive network management case. Penetration of distributed generation in the network is favourable for the DSO for low penetration levels, but becomes unfavourable the higher the penetration rate and the more concentrated the distributed generation in the network. However, it should be noted that the negative results are relatively small for the majority of the cases analyzed: the net impact of distributed generation penetration is mostly within the range of $8 \%$ of the 'business as usual' profit DSOs make. 


\begin{tabular}{|c|c|c|c|c|c|c|}
\hline \multicolumn{5}{|c|}{ Parameter } & \multicolumn{2}{|c|}{ Impact on DSO net profit } \\
\hline $\begin{array}{l}\text { Level } \\
\text { DG } \\
(\mathrm{MW})\end{array}$ & $\begin{array}{l}\text { Net- } \\
\text { work } \\
\text { type }\end{array}$ & $\begin{array}{l}\text { Concentra- } \\
\text { tion DG }\end{array}$ & Type of DG & $\begin{array}{l}\text { Network } \\
\text { manage- } \\
\text { ment type }\end{array}$ & $\begin{array}{c}\text { Excluding } \\
\text { potential } \\
\text { deferred } \\
\text { investment }\end{array}$ & $\begin{array}{l}\text { Including } \\
\text { potential } \\
\text { deferred } \\
\text { investment }\end{array}$ \\
\hline 100 & $\mathrm{R}$ & $\mathrm{H}$ & $\mathrm{I}$ & $\mathrm{P}$ & $7.8 \%$ & $29.6 \%$ \\
\hline 100 & $\mathrm{R}$ & $\mathrm{H}$ & $\mathrm{I}$ & A & $9.2 \%$ & $31.0 \%$ \\
\hline 100 & $\mathrm{R}$ & $\mathrm{H}$ & $\mathrm{NI}$ & $\mathrm{P}$ & $-7.0 \%$ & $14.8 \%$ \\
\hline 100 & $\mathrm{R}$ & $\mathrm{H}$ & $\mathrm{NI}$ & $\mathrm{A}$ & $-6.7 \%$ & $15.1 \%$ \\
\hline 50 & $\mathrm{R}$ & $\mathrm{L}$ & I & $\mathrm{P}$ & $2.1 \%$ & $12.9 \%$ \\
\hline 50 & $\mathrm{R}$ & $\mathrm{L}$ & $\mathrm{I}$ & $\mathrm{A}$ & $2.1 \%$ & $12.9 \%$ \\
\hline 50 & $\mathrm{R}$ & $\mathrm{L}$ & $\mathrm{NI}$ & $\mathrm{P}$ & $5.2 \%$ & $15.9 \%$ \\
\hline 50 & $\mathrm{R}$ & $\mathrm{L}$ & $\mathrm{NI}$ & $\mathrm{A}$ & $5.2 \%$ & $15.9 \%$ \\
\hline 200 & $\mathrm{R}$ & $\mathrm{H}$ & $\mathrm{I}$ & $\mathrm{P}$ & $-16.2 \%$ & $1.0 \%$ \\
\hline 200 & $\mathrm{R}$ & $\mathrm{H}$ & $\mathrm{I}$ & $\mathrm{A}$ & $-21.6 \%$ & $-4.4 \%$ \\
\hline 200 & $\mathrm{R}$ & $\mathrm{H}$ & $\mathrm{NI}$ & $\mathrm{P}$ & $-44.7 \%$ & $-27.5 \%$ \\
\hline 200 & $\mathrm{R}$ & $\mathrm{H}$ & $\mathrm{NI}$ & $\mathrm{A}$ & $-57.3 \%$ & $-40.0 \%$ \\
\hline 100 & $\mathrm{R}$ & $\mathrm{L}$ & $\mathrm{I}$ & $\mathrm{P}$ & $-4.3 \%$ & $17.6 \%$ \\
\hline 100 & $\mathrm{R}$ & $\mathrm{L}$ & $\mathrm{I}$ & $\mathrm{A}$ & $-4.5 \%$ & $17.4 \%$ \\
\hline 100 & $\mathrm{R}$ & $\mathrm{L}$ & $\mathrm{NI}$ & $\mathrm{P}$ & $0.3 \%$ & $22.2 \%$ \\
\hline 100 & $\mathrm{R}$ & $\mathrm{L}$ & $\mathrm{NI}$ & A & $0.3 \%$ & $22.2 \%$ \\
\hline 100 & $\mathrm{U}$ & $\mathrm{H}$ & I & $\mathrm{P}$ & $-1.2 \%$ & $20.6 \%$ \\
\hline 100 & $\mathrm{U}$ & $\mathrm{H}$ & I & $\mathrm{A}$ & $4.6 \%$ & $26.4 \%$ \\
\hline 100 & $\mathrm{U}$ & $\mathrm{H}$ & $\mathrm{NI}$ & $\mathrm{P}$ & $-10.5 \%$ & $11.3 \%$ \\
\hline 100 & $\mathrm{U}$ & $\mathrm{H}$ & $\mathrm{NI}$ & $\mathrm{A}$ & $-3.8 \%$ & $18.0 \%$ \\
\hline 50 & $\mathrm{U}$ & $\mathrm{L}$ & I & $\mathrm{P}$ & $-8.4 \%$ & $2.3 \%$ \\
\hline 50 & $\mathrm{U}$ & $\mathrm{L}$ & $\mathrm{I}$ & A & $-1.6 \%$ & $9.1 \%$ \\
\hline 50 & $\mathrm{U}$ & $\mathrm{L}$ & $\mathrm{NI}$ & $\mathrm{P}$ & $2.6 \%$ & $13.4 \%$ \\
\hline 50 & $\mathrm{U}$ & $\mathrm{L}$ & $\mathrm{NI}$ & A & $0.4 \%$ & $11.2 \%$ \\
\hline 200 & $\mathrm{U}$ & $\mathrm{H}$ & $\mathrm{I}$ & $\mathrm{P}$ & $-26.4 \%$ & $-9.2 \%$ \\
\hline 200 & $\mathrm{U}$ & $\mathrm{H}$ & $\mathrm{I}$ & A & $-32.9 \%$ & $-15.7 \%$ \\
\hline 200 & $\mathrm{U}$ & $\mathrm{H}$ & $\mathrm{NI}$ & $\mathrm{P}$ & $-41.1 \%$ & $-23.9 \%$ \\
\hline 200 & $\mathrm{U}$ & $\mathrm{H}$ & NI & A & $-51.9 \%$ & $-34.6 \%$ \\
\hline 100 & $\mathrm{U}$ & $\mathrm{L}$ & I & $\mathrm{P}$ & $-10.6 \%$ & $11.3 \%$ \\
\hline 100 & $\mathrm{U}$ & $\mathrm{L}$ & I & $\mathrm{A}$ & $-2.3 \%$ & $19.6 \%$ \\
\hline 100 & $\mathrm{U}$ & $\mathrm{L}$ & $\mathrm{NI}$ & $\mathrm{P}$ & $1.2 \%$ & $23.2 \%$ \\
\hline 100 & $\mathrm{U}$ & $\mathrm{L}$ & $\mathrm{NI}$ & $\mathrm{A}$ & $0.1 \%$ & $22.1 \%$ \\
\hline
\end{tabular}

Table 3. Incremental impact of the integration of distributed generation on the financial position of a DSO (DG = distributed generation, $\mathrm{U}=$ urban network, $\mathrm{R}=$ rural network, $\mathrm{H}=$ high penetration, $\mathrm{L}=$ low penetration, $\mathrm{I}=$ intermittent, $\mathrm{NI}=$ non-intermittent, $\mathrm{P}=$ passive network management, $\mathrm{A}=$ active network management)

The added value of distributed generation with respect to the investment deferral for connections to the higher voltage network levels can be substantial. Considering the 
maximum replacement values of distributed generation, it can be expected that the overall impact of distributed generation penetration on the DSO business can be neutral or positive in the majority of cases. However, the realization of this positive value for the DSOs is dependent on a larger number of non-distributed generation related factors and is beyond the scope of this investigation (e.g. load growth dynamics and the status of interconnection equipment). However, we hypothesize that it is unlikely that the full replacement value is going to be realised in all cases. This is something to be tested in further research. Observing the differential impact on the DSO under passive and active network management we conclude that there is an implicit incentive for the DSO to adopt an active network management approach in a number of cases, in particular the case where distributed generation penetration is low or medium.

The observation that an increased penetration of distributed generation is negative in cases where there is no actual replacement value for the DSO does not automatically justify adaptation of distribution network regulation. When assessing the necessity of such adaptation one also needs to take into account potential positive impacts on the DSO brought about by increased distributed generation penetration. These could for example emerge in the field of ancillary services provision and demand response mechanisms (Strbac 2008, Jansen et al. 2007). The DSO can for example act as an intermediary in the provision of these network related types of services due to the operational network information acquired through implementation of active network management. These services would imply a new source of revenues for the DSO that might compensate for negative impact with regard to network operations and investment due to increased distributed generation penetration. Additional research on the significance of this type of business opportunities for DSOs is required. For now we assume that these opportunities do not (fully) compensate the negative impact of the type shown above and therefore proceed to propose possible improvements for current network regulation that can mitigate the negative impact.

\subsection{Impact of adaptations to distribution network regulation}

The negative impact of distributed generation integration on the DSO's financial position as reported above may hamper the deployment of distributed generation resulting in a 'conflict' with the national and European policy objectives for CHP and RES-E. To solve this problem the additional costs of distributed generation integration should be socialized among all customers connected to the network, i.e. electricity consumers and generators alike. The network costs for connecting and integrating distributed generation is then treated in the same way as network costs related to electricity consumption. This reflects the role of the distribution network: providing access to the electricity market for consumers and (distributed) generators under similar conditions. The extra network costs induced by distributed generation connections can be allocated to consumers and distributed generation operators through the use of system charges. These tariffs (connection charges and use of system charges) are calculated from the TAR by taking into account the number of connections, size of connections, amounts of $\mathrm{kWh}$ and $\mathrm{kW}_{\text {peak, }}$ et cetera.

With the revenue cap formula (Equation 1) as a starting point, five alternative ways to compensate for the negative impact of distributed generation penetration have been tested. The DSO financial model was applied to test the effectiveness of four of these alternatives. A 
fifth alternative is to consider distributed generation as a cost driver in the DSO benchmarking exercise. However, the model is not capable of analysing this option. The four alternatives for adaptation of distribution network regulation are:

1. Automatically allowing for investments due to distributed generation in the regulated asset base;

2. Compensation related to an indicator for the presence and impact of distributed generation in the distribution network;

3. Including a direct revenue driver in the regulatory formula based on distributed generation;

4. A combination of alternatives (1) and (3)

Below we briefly expand on these alternatives.

An automatic allowance of investment expenditures related to the integration of distributed generation compensates for the possible negative impact of the penetration of distributed generation with respect to capital expenditures but not with respect to operational expenditures. Theoretically, the pass-through of distributed generation related capital expenditures can lie between 0 and 100\%. A 100\% pass-through in fact implies a cost-plus arrangement for distributed generation related expenditures. Such a high pass-through factor might not be desirable in a large number of cases since especially for low levels of distributed generation the DSO can in fact benefit from the presence of distributed generation. Moreover, a pass-through factor of less than $100 \%$ will provide an incentive to limit these investments. We propose a partial pass-through of expenditures related to the integration of distributed generation with the pass-through factor increasing with the level of distributed generation in the distribution network. In our analysis we apply a $30 \%$ passthrough is for a low distributed generation penetration rate, $70 \%$ for a medium and $90 \%$ for a high distributed generation penetration rate. This type of compensation measure may be described by the following formula: ${ }^{4}$

$$
T A R_{t}=T A R_{t-1}(1-X)+y \% \cdot I_{t}^{D G}
$$

Where

$y=$ Share of eligible distributed generation related investments in distribution network assets

$I_{t}^{D G}=$ Total eligible distributed generation related investments in distribution network assets in year $t$

A second alternative is correcting the increase in DSO efficiency requirements over time (the X-factor) with an individual DSO based factor representing the presence and impact of distributed generation in its network. Such a factor could be based on an index capturing the

4 Assuming that demand growth is zero so that the adjustment factor AF (see equation 1) is equal to zero. 
impact of distributed generation on distribution networks. In such an index the different context specific parameters, such as amount, concentration, type of network and the like, determining the actual impact of distributed generation could be included. Formula-wise this would encompass the following:

$$
T A R_{t}=T A R_{t-1}\left(1-X+K_{\text {Ind }}\right)
$$

For our exploratory analysis we have set the values for $K_{\text {Ind }}$ at $0.75 \%$ for a distributed generation penetration level of $11 \%, 1.5 \%$ for a penetration level of $23 \%, 5 \%$ for a penetration level of $46 \%$, and $10 \%$ for a penetration level of $91 \%$.

A third possible alternative is the straightforward inclusion of a revenue driver based on distributed generation in the revenue cap formula, where the revenue driver can be based on the amount of distributed generation capacity in the distribution network, or energy delivered by distributed generation to the distribution network. This results in the following formula:

$$
T A R_{t}=T A R_{t-1}(1-X)+F_{1} \cdot k W^{D G}+F_{2} \cdot M W h^{D G}
$$

In our exploratory example the additional revenue driver is based on both the total amount of distributed generation capacity in the network $\left(F_{1}=2.5 € / \mathrm{kW}\right.$ for a low, $F_{1}=2 € / \mathrm{kW}$ for a medium and $F_{1}=1 € / \mathrm{kW}$ for high a distributed generation penetration) and the electricity generated by distributed generation units in the network $\left(\mathrm{F}_{2}=0 € / \mathrm{MWh}\right.$ for a low, $\mathrm{F}_{2}=2.5$ $€ / \mathrm{MWh}$ for a medium and $\mathrm{F}_{2}=3.5 € / \mathrm{MWh}$ for a high distributed generation penetration).

Finally, as a fourth alternative we test a combination of alternatives 1 and 3 . The DSO is allowed to pass-through a certain percentage of additional capital expenditures due to increased penetration of distributed generation in the network and is allowed additional revenue based on an 'energy' based revenue driver:

$$
T A R_{t}=T A R_{t-1}(1-X)+y \% \cdot I_{t}^{D G}+F \cdot M W h^{D G}
$$

In our analysis the rate for total eligible distributed generation related investments $\left(\mathrm{I}_{\mathrm{t}} \mathrm{DG}\right)$ is $50 \%$ and the direct revenue driver $(\mathrm{F})$ has the value of $2 € / \mathrm{MWh}$.

Table 4 shows the incremental financial impact for the DSO of increasing the amount of distributed generation in the network in the reference case, where regulation is not adapted, and the potential deferred investment value is excluded, and the four alternative cases. 


\begin{tabular}{|c|c|c|c|c|c|c|c|c|c|}
\hline \multicolumn{5}{|c|}{ Parameter } & Reference & \multicolumn{4}{|c|}{ Regulatory adaptations } \\
\hline 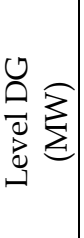 & 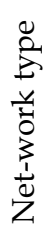 & 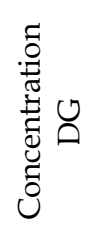 & 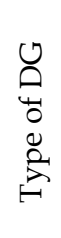 & 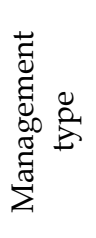 & 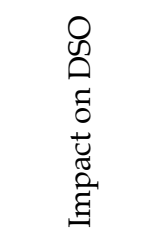 & 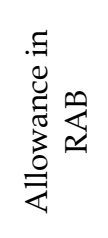 & 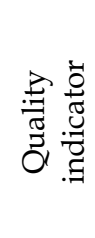 & 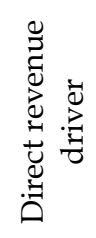 & 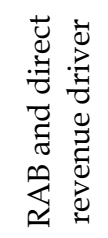 \\
\hline 100 & $\mathrm{R}$ & $\mathrm{H}$ & I & $\mathrm{P}$ & $7.8 \%$ & $10.6 \%$ & $12.7 \%$ & $9.9 \%$ & $17.2 \%$ \\
\hline 100 & $\mathrm{R}$ & $\mathrm{H}$ & I & $\mathrm{A}$ & $9.2 \%$ & $10.6 \%$ & $14.1 \%$ & $11.3 \%$ & $16.3 \%$ \\
\hline 100 & $\mathrm{R}$ & $\mathrm{H}$ & NI & $\mathrm{P}$ & $-7.0 \%$ & $1.0 \%$ & $11.5 \%$ & $9.3 \%$ & $9.1 \%$ \\
\hline 100 & $\mathrm{R}$ & $\mathrm{H}$ & $\mathrm{NI}$ & $\mathrm{A}$ & $-6.7 \%$ & $-1.8 \%$ & $11.7 \%$ & $9.5 \%$ & $7.3 \%$ \\
\hline 50 & $\mathrm{R}$ & $\mathrm{L}$ & $\mathrm{I}$ & $\mathrm{P}$ & $2.1 \%$ & $2.1 \%$ & $4.6 \%$ & $3.2 \%$ & $4.5 \%$ \\
\hline 50 & $\mathrm{R}$ & $\mathrm{L}$ & $\mathrm{I}$ & $\mathrm{A}$ & $2.1 \%$ & $2.1 \%$ & $4.6 \%$ & $3.2 \%$ & $4.5 \%$ \\
\hline 50 & $\mathrm{R}$ & $\mathrm{L}$ & $\mathrm{NI}$ & $\mathrm{P}$ & $5.2 \%$ & $5.2 \%$ & $10.1 \%$ & $6.2 \%$ & $9.8 \%$ \\
\hline 50 & $\mathrm{R}$ & $\mathrm{L}$ & $\mathrm{NI}$ & $\mathrm{A}$ & $5.2 \%$ & $5.2 \%$ & $10.1 \%$ & $6.2 \%$ & $9.8 \%$ \\
\hline 200 & $\mathrm{R}$ & $\mathrm{H}$ & I & $\mathrm{P}$ & $-16.2 \%$ & $2.8 \%$ & $4.7 \%$ & $5.4 \%$ & $8.9 \%$ \\
\hline 200 & $\mathrm{R}$ & $\mathrm{H}$ & I & A & $-21.6 \%$ & $-6.6 \%$ & $-0.2 \%$ & $1.6 \%$ & $1.7 \%$ \\
\hline 200 & $\mathrm{R}$ & $\mathrm{H}$ & $\mathrm{NI}$ & $\mathrm{P}$ & $-44.7 \%$ & $-18.3 \%$ & $-1.8 \%$ & $3.0 \%$ & $-3.8 \%$ \\
\hline 200 & $\mathrm{R}$ & $\mathrm{H}$ & $\mathrm{NI}$ & $\mathrm{A}$ & $-57.3 \%$ & $-36.4 \%$ & $\begin{array}{c}- \\
13.6 \%\end{array}$ & $-8.2 \%$ & $-19.0 \%$ \\
\hline 100 & $\mathrm{R}$ & $\mathrm{L}$ & I & $\mathrm{P}$ & $-4.3 \%$ & $-2.4 \%$ & $1.9 \%$ & $-1.3 \%$ & $4.1 \%$ \\
\hline 100 & $\mathrm{R}$ & $\mathrm{L}$ & I & A & $-4.5 \%$ & $-3.2 \%$ & $1.7 \%$ & $-1.5 \%$ & $3.1 \%$ \\
\hline 100 & $\mathrm{R}$ & $\mathrm{L}$ & $\mathrm{NI}$ & $\mathrm{P}$ & $0.3 \%$ & $3.7 \%$ & $16.7 \%$ & $14.5 \%$ & $12.0 \%$ \\
\hline 100 & $\mathrm{R}$ & $\mathrm{L}$ & $\mathrm{NI}$ & A & $0.3 \%$ & $2.5 \%$ & $16.6 \%$ & $14.5 \%$ & $11.2 \%$ \\
\hline 100 & $\mathrm{U}$ & $\mathrm{H}$ & $\mathrm{I}$ & $\mathrm{P}$ & $-1.2 \%$ & $3.8 \%$ & $4.1 \%$ & $1.3 \%$ & $11.7 \%$ \\
\hline 100 & $\mathrm{U}$ & $\mathrm{H}$ & I & $\mathrm{A}$ & $4.6 \%$ & $5.6 \%$ & $9.5 \%$ & $6.7 \%$ & $10.8 \%$ \\
\hline 100 & $\mathrm{U}$ & $\mathrm{H}$ & $\mathrm{NI}$ & $\mathrm{P}$ & $-10.5 \%$ & $2.7 \%$ & $9.0 \%$ & $6.8 \%$ & $9.8 \%$ \\
\hline 100 & $\mathrm{U}$ & $\mathrm{H}$ & $\mathrm{NI}$ & $\mathrm{A}$ & $-3.8 \%$ & $-1.0 \%$ & $13.7 \%$ & $11.5 \%$ & $8.2 \%$ \\
\hline 50 & $\mathrm{U}$ & $\mathrm{L}$ & I & $\mathrm{P}$ & $-8.4 \%$ & $-2.3 \%$ & $-5.0 \%$ & $-6.9 \%$ & $3.9 \%$ \\
\hline 50 & $\mathrm{U}$ & $\mathrm{L}$ & $\mathrm{I}$ & A & $-1.6 \%$ & $0.6 \%$ & $1.3 \%$ & $-0.1 \%$ & $4.3 \%$ \\
\hline 50 & $\mathrm{U}$ & $\mathrm{L}$ & NI & $\mathrm{P}$ & $2.6 \%$ & $2.6 \%$ & $5.3 \%$ & $1.5 \%$ & $7.3 \%$ \\
\hline 50 & $\mathrm{U}$ & $\mathrm{L}$ & $\mathrm{NI}$ & A & $0.4 \%$ & $2.3 \%$ & $5.3 \%$ & $1.5 \%$ & $8.2 \%$ \\
\hline 200 & $\mathrm{U}$ & $\mathrm{H}$ & I & $\mathrm{P}$ & $-26.4 \%$ & $7.2 \%$ & $-4.7 \%$ & $-2.5 \%$ & $9.7 \%$ \\
\hline 200 & $\mathrm{U}$ & $\mathrm{H}$ & I & A & $-32.9 \%$ & $4.2 \%$ & $\begin{array}{c}- \\
10.9 \% \\
\end{array}$ & $-9.0 \%$ & $6.2 \%$ \\
\hline 200 & $\mathrm{U}$ & $\mathrm{H}$ & $\mathrm{NI}$ & $\mathrm{P}$ & $-41.1 \%$ & $3.4 \%$ & $1.6 \%$ & $5.5 \%$ & $8.6 \%$ \\
\hline 200 & $\mathrm{U}$ & $\mathrm{H}$ & $\mathrm{NI}$ & A & $-51.9 \%$ & $-2.8 \%$ & $-8.4 \%$ & $-2.8 \%$ & $1.6 \%$ \\
\hline 100 & $\mathrm{U}$ & $\mathrm{L}$ & I & $\mathrm{P}$ & $-10.6 \%$ & $-4.4 \%$ & $-4.0 \%$ & $-7.6 \%$ & $4.8 \%$ \\
\hline 100 & $\mathrm{U}$ & $\mathrm{L}$ & $\mathrm{I}$ & A & $-2.3 \%$ & $-1.7 \%$ & $3.3 \%$ & $0.5 \%$ & $3.8 \%$ \\
\hline 100 & $\mathrm{U}$ & $\mathrm{L}$ & $\mathrm{NI}$ & $\mathrm{P}$ & $1.2 \%$ & $1.2 \%$ & $17.6 \%$ & $15.4 \%$ & $10.6 \%$ \\
\hline 100 & $\mathrm{U}$ & $\mathrm{L}$ & $\mathrm{NI}$ & A & $0.1 \%$ & $1.2 \%$ & $16.5 \%$ & $14.3 \%$ & $10.2 \%$ \\
\hline
\end{tabular}

Table 4. Incremental impact of the integration of distributed generation on the financial position of a DSO for in the case of no regulatory adaptation (reference case) and in the case of four alternative adaptations to regulation ( $D G=$ distributed generation, $U=$ urban 
network, $\mathrm{R}$ = rural network, $\mathrm{H}$ = high penetration, $\mathrm{L}=$ low penetration, $\mathrm{I}=$ intermittent, $\mathrm{NI}=$ non-intermittent, $\mathrm{P}=$ passive network management, $\mathrm{A}=$ active network management)

Our results indicate that there is no 'one size fits all' solution for neutralizing the negative impact of distributed generation penetration on the financial position of a DSO. Since the negative impact of distributed generation through either operational expenditures (distribution losses) or capital expenditures (network upgrades) is dominant, a specific regulatory arrangement with compensatory elements based on either 'energy produced by distributed generation' or 'distributed generation capacity connected' can not fully compensate the one DSO without unnecessarily 'overcompensating' other DSOs. The most successful regulatory improvement seems to be the combination of a special allowance and a direct revenue driver. When applying this regulatory alternative DSOs will be able to recover their costs. It should be noted that a minor 'overcompensation' of DSOs for the negative impact they experience from distributed generation penetration in the network might effectively work as an incentive to optimally facilitate the integration of additional distributed generation within the distribution network.

\section{Discussion}

Our analysis has shown that increasing presence of distributed generation in distribution networks is not always favourable where specific network and distributed generation characteristics play a crucial role. We analyzed the economic impact of an increasing penetration of distributed generation in distribution networks on the financial position of the DSO taking into account a number of network and distributed generation characteristics. In addition, we included two different network management philosophies (passive and active network management) in the analysis. We find that DSOs operating under a passive network management regime generally do not profit from the presence of distributed generation in their distribution network, except at low distributed generation penetration levels: network reinforcement costs increase with the level of distributed generation penetration. DSOs adopting active network management are generally faced with similar general results as DSOs adopting passive network management. Penetration of distributed generation in the network is favourable for the DSO for low penetration levels, but becomes unfavourable the higher the penetration rate and the more concentrated the presence of distributed generation in the distribution network.

The added value of distributed generation with respect to the deferral of investments at the grid supply point (the connection with the higher voltage level network) can be substantial. However, the realisation of this positive value for DSOs is dependent on a larger number of factors that are beyond the scope of our research. These relate to the load growth dynamics and the status of interconnection equipment (economic lifetime and depreciation). Considering the maximum replacement values of distributed generation, it might be expected that the overall impact of distributed generation penetration on the DSO business, can be neutral or positive in the majority of cases. Observing a differential impact on the DSO under passive and active network management we conclude that there is an implicit incentive for the DSO to adopt an active network management approach in a number of cases, in particular the case where distributed generation penetration is low or medium. For 
cases with a high penetration of distributed generation definitive conclusions cannot be drawn: more research is needed on the costs for the DSO when combining passive and active network management elements.

Regarding the implications of the analysis for the need for alternative regulatory arrangements we note that there are several cases where the DSO is negatively impacted by the increasing penetration of distributed generation, regardless of the network management philosophy. This implies that an alternative regulatory arrangement compensating the DSO for the negative impact might be warranted. Moreover, we have seen that in such cases the incentive for DSOs to move from a passive network management approach to an active network management approach is not always present.

From the analysis on regulatory improvements we found that an alternative regulatory arrangement based on a combination of a special regulated asset base allowance and a direct revenue driver seems most successful in compensating the negative distributed generation impact on DSOs. When applying this regulatory improvement DSOs will be able to recover their costs and at the same time are stimulated to integrate existent and new types of distributed generation without at the same time largely 'overcompensating' some DSOs that experience little or even no negative impact.

The most sophisticated revenue driver seems to be a driver that accounts for all connected $\mathrm{kW}$ of distributed generation capacity as well as for all $\mathrm{kWh}$ of distributed generation electricity fed into the grid. Regarding the possible 'overcompensation' caused by regulatory improvements we noted that a minor 'overcompensation' in practice might work as an incentive to fully facilitate distributed generation integration within their distribution network.

Finally, it should be noted that the analysis in this paper is based on shallow network charging and constant UoS charging principles. Theoretically, the operators of distributed generation units could be given more efficient signals regarding siting and timing of production of distributed electricity generation. This principle could be implemented through a move to (i) shallowish or deep connection cost charging or (ii) time and location differentiated UoS charges 5 . This could substantially reduce the costs of network integration for the DSO, both in operational and capital costs. However, successful implementation of time and location dependent network charges is not to be expected in the short to mediumrun for technological, political and regulatory reasons.

\section{Recommendations}

Our analysis allows us to draw some policy recommendations. Firstly, current regulation of DSOs should recognise the differential impact of an increasing level of distributed generation on the financial position of the DSO and therefore regulators should investigate alternative regulation that can sufficiently take into account the drivers behind this impact. Secondly, as a specification of the first recommendation, we suggest to implement a

5 The latter is basically a nodal pricing system (Schweppe et al., 1988). 
regulatory formula where the impact of distributed generation on both operating expenditures (with the main driver being electricity generated by distributed generation units, impacting distribution losses) and capital expenditures (with the main drivers the amount of distributed generation units connected to the distribution network) are included. Thirdly, in determining the specific values in the alternative regulatory formula we would recommend to aim for some 'overcompensation' of any negative impact of distributed generation penetration on DSOs in order to provide them with an explicit incentive to facilitate and accommodate new distributed generation connections in their distribution networks. Fourthly, when considering the above recommendations on the neutralization and possible incentivisation of DSOs it should be kept in mind that the desirability of regulation aimed at these aspects is intertwined with the developments in the field of ancillary services provision by DSOs. This was discussed in Jansen et al. (2007). On the one hand, DSOs might need to be compensated for the negative impact following the penetration of distributed generation in distribution networks. On the other hand, if DSOs benefit from the provision of ancillary services enabled by the increasing presence of distributed generation, the DSO should compensate the distributed generation operators for this. Netting both impacts implies that valuable economic signals are lost. Changes in regulation should therefore be targeted at either one, or both, described impacts. In the longrun, implementation of location and time dependent network charges could counter the negative impacts for DSOs described in this paper. However, considering the fact that DSOs in some countries are already experiencing the negative impact of large shares of distributed generation in the network, solutions to this particular problem need to be found in adaptation of current regulation in the short-run.

In addition to the recommendations for policy and regulation we can also draw some recommendations for future research. Firstly, further research is needed into the issue of deferred investment value. Our analysis showed that this is a very important variable in any financial analysis on the integration of distributed generation in electricity systems. Secondly, the focus of our analysis was on the integration of distributed generation and its impact on the (financial position of the) DSO. The underlying goal of the research was the efficient integration of renewable and distributed generation in current electricity systems. Since this process of integration affects all actors in the electricity system a focus on just the distribution network and its operator is not sufficient. In the end what should be assessed is the overall socio-economic optimal integration of renewable and distributed generation. In other words: how can we optimally facilitate the transition to an electricity system with a larger share of renewable and distributed electricity generation at the least cost for society as a whole? This requires an integral impact analysis of an increase in the penetration of distributed generation on society as a whole, including the impact on networks (distribution and transmission), markets (wholesale, balancing, ancillary services) and the environment (environmental externalities.

\section{References}

Ackermann, T.; Andersson, G. \& Söder, L. (2001). Distributed Generation: A Definition. Electric Power Systems Research, Vol. 57, No. 3, April 2001, 195-204. 
Barth, R.; Weber, C.; \& Swider, D.J. (2008). Distribution of Costs Induced by the Integration of RES-E Power. Energy Policy, vol. 36, No. 8, August 2008, 3107-3115.

Cao, D.M.; Pudjianto, D.; Grenard, S.; Strbac, G.; Martikainen, A.; Kärkkäinen, S. \& Farin, J. (2007). Costs and Benefits of DG Connections to Grid System. DG Grid report D8.

Cossent, R.; Gomez, T.\& Frias, P. (2009). Towards a Future with Large Penetration of Distributed Generation: Is the Current Regulation of Electricity Distribution Ready? Regulatory Recommendations under a European Perspective, Energy Policy, Vol. 37, No. 3, March 2009, pp. 1145-1155.

de Joode, J.; Jansen, J.C.; van der Welle, A.J. \& Scheepers, M.J.J. (2009). Increasing Penetration of Renewable and Distributed Electricity Generation and the Need for Different Network Regulation. Energy Policy, Vol. 37, No. 8, August 2009, $2907-$ 2915.

European Commission (EC) (2008). European Energy and Transport Trends to 2030-update 2007. European Commission, Directorate-General for Energy and Transport, ISBN 97892-79-07620-6, Office for Official Publications of the European Communities, Luxembourg, April 2008.

Gil, H.A. \& Joos, G. (2006). On the Quantification of the Network Capacity Deferral Value of Distributed Generation, IEEE Transactions on Power Systems, Vol. 21, No. 4, November 2006, Pages 1592-1599.

Jansen, J.C.; Van der Welle, A.J.; \& De Joode, J. (2007). The evolving Role of the DSO in Efficiently Accommodating Distributed Generation. ECN report ECN-E--07-063, September 2007, Petten.

Joskow, P.L. (2005). Regulation of Natural Monopolies. Massachusetts Institute of Technology, Centre for Energy and Environmental Policy Research. Working Paper 0508.

Joskow, P.L. (2006). Incentive Regulation in Theory and Practice: Electricity Distribution and Transmission Networks. Cambridge Working Papers in Economics CWPE0607, Electricity Policy Research Group Working Paper EPRG 0511.

McDonald, J. (2008). Adaptive Intelligent Power Systems: Active Distribution Networks. Energy Policy, Vol. 36, No. 12, December 2008, 4346-4351.

Méndez, V.H.; Rivier, J.; de la Fuente, J.I.; Gomez, T.; Arceluz, J.; Marin, J. \& Madurga, A. (2006a). Impact of Distributed Generation on Distribution Investment Deferral, Electrical Power and Energy Systems, Vol. 28, No. 4, May 2006, 244-252.

Méndez, V.H.; Rivier, J. , Gómez, T. (2006b). Assessment of Energy Distribution Losses for Increasing Penetration of Distributed Generation. IEEE Transactions on Power Systems, Vol. 21, No. 2, May 2006, 533-540.

Peças Lopes, J.A.; Hatziargyriou, N.; Mutale, J.; Djapic, P. \& Jenkins, N. (2007). Integrating Distributed Generation into Electric Power Systems: A Review of Drivers, Challenges and Opportunities. Electric Power Systems Research, Vol. 77, No. 9, July 2007, 1189-1203.

Pepermans, G.; Driesen, J.; Haeseldonckx, D.; Belmans, R. \& D'haeseleer, W. (2005). Distributed Generation: Definition, Benefits and Issues. Energy Policy, Vol. 33, No. 6, April 2005, 787-798.

Pudjianto, D.; Cao, D.M..; Grenard, S. \& Strbac, G. (2006). Method for Monetarisation of Cost and Benefits of DG Options. University of Manchester and Imperial College London, January 2006. DG-Grid project D7. 
Rudnick, H. \& Donoso, J.A. (2000). Integration of Price Cap and Yardstick Competition Schemes in Electrical Distribution Regulation. IEEE Transactions on Power Systems, Vol. 15, No. 4, November 2000, 1428-1433.

Scheepers, M.J.J. (2004). Policy and Regulatory Road Maps for the Integration of Distributed Generation and the Development of Sustainable Electricity Networks. Final report of the Sustelnet project, ECN-C--04-034, August 2004, Petten.

Schweppe, F.C.; Caramanis, M.C.; Tabors, R.D. \& Bohn, R.E. (1988). Spot Pricing of Electricity, Kluwer Academic Publishers.

Skytte, K. \& Ropenus, S. (2007). Regulatory Review and Barriers for the Electricity Supply System for Distributed Generation in the EU-15. International Journal of Distributed Energy Resources, Vol. 3, No. 3, July-September 2007, 243-257.

Strbac, G. (2002). Impact of Dispersed Generation on Distribution Systems: A European Perspective. Power Engineering Society Winter Meeting, Vol. 1, August 2002, 118-120.

Woodman, B. \& Baker, P. (2008). Regulatory Frameworks for Decentralised Energy. Energy Policy, Vol. 36, No. 12, December 2008, 4527-4531. 


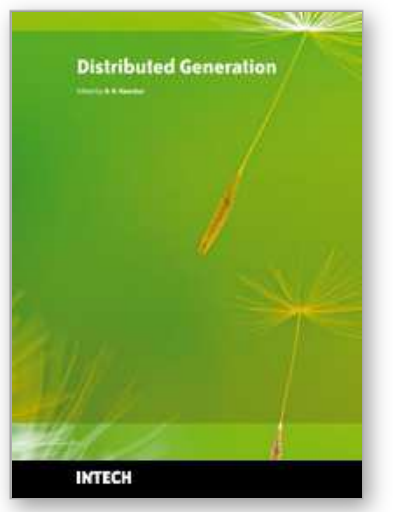

\author{
Distributed Generation \\ Edited by D N Gaonkar
}

ISBN 978-953-307-046-9

Hard cover, 406 pages

Publisher InTech

Published online 01, February, 2010

Published in print edition February, 2010

In the recent years the electrical power utilities have undergone rapid restructuring process worldwide. Indeed, with deregulation, advancement in technologies and concern about the environmental impacts, competition is particularly fostered in the generation side, thus allowing increased interconnection of generating units to the utility networks. These generating sources are called distributed generators (DG) and defined as the plant which is directly connected to distribution network and is not centrally planned and dispatched. These are also called embedded or dispersed generation units. The rating of the DG systems can vary between few $\mathrm{kW}$ to as high as $100 \mathrm{MW}$. Various new types of distributed generator systems, such as microturbines and fuel cells in addition to the more traditional solar and wind power are creating significant new opportunities for the integration of diverse DG systems to the utility. Interconnection of these generators will offer a number of benefits such as improved reliability, power quality, efficiency, alleviation of system constraints along with the environmental benefits. Unlike centralized power plants, the DG units are directly connected to the distribution system; most often at the customer end. The existing distribution networks are designed and operated in radial configuration with unidirectional power flow from centralized generating station to customers. The increase in interconnection of $D G$ to utility networks can lead to reverse power flow violating fundamental assumption in their design. This creates complexity in operation and control of existing distribution networks and offers many technical challenges for successful introduction of DG systems. Some of the technical issues are islanding of DG, voltage regulation, protection and stability of the network. Some of the solutions to these problems include designing standard interface control for individual DG systems by taking care of their diverse characteristics, finding new ways to/or install and control these DG systems and finding new design for distribution system. DG has much potential to improve distribution system performance. The use of DG strongly contributes to a clean, reliable and cost effective energy for future. This book deals with several aspects of the DG systems such as benefits, issues, technology interconnected operation, performance studies, planning and design. Several authors have contributed to this book aiming to benefit students, researchers, academics, policy makers and professionals. We are indebted to all the people who either directly or indirectly contributed towards the publication of this book.

\title{
How to reference
}

In order to correctly reference this scholarly work, feel free to copy and paste the following:

Jeroen de Joode, Adriaan van der Welle and Jaap Jansen (2010). Distributed Generation and the Regulation of Distribution Networks, Distributed Generation, D N Gaonkar (Ed.), ISBN: 978-953-307-046-9, InTech, Available from: http://www.intechopen.com/books/distributed-generation/distributed-generation-and-theregulation-of-distribution-networks 
open science | open minds

InTech Europe

University Campus STeP Ri

Slavka Krautzeka 83/A

51000 Rijeka, Croatia

Phone: +385 (51) 770447

Fax: +385 (51) 686166

www.intechopen.com
InTech China

Unit 405, Office Block, Hotel Equatorial Shanghai

No.65, Yan An Road (West), Shanghai, 200040, China

中国上海市延安西路65号上海国际贵都大饭店办公楼 405 单元

Phone: +86-21-62489820

Fax: +86-21-62489821 
(C) 2010 The Author(s). Licensee IntechOpen. This chapter is distributed under the terms of the Creative Commons Attribution-NonCommercialShareAlike-3.0 License, which permits use, distribution and reproduction for non-commercial purposes, provided the original is properly cited and derivative works building on this content are distributed under the same license. 